\title{
Effect of the inhibition of CYP3A4 or CYP2D6 on the pharmacokinetics and pharmacodynamics of oxycodone
}

\author{
Oliver Kummer • Felix Hammann • Claudine Moser • \\ Olivier Schaller • Jürgen Drewe • Stephan Krähenbühl
}

Received: 1 May 2010 /Accepted: 25 August 2010/Published online: 21 September 2010

(C) Springer-Verlag 2010

\begin{abstract}
Purpose The main metabolic pathways of oxycodone, a potent opioid analgetic, are N-demethylation (CYP3A4) to inactive noroxycodone and O-demethylation (CYP2D6) to active oxymorphone. We performed a three-way, placebocontrolled, double-blind cross-over study to assess the pharmacokinetic and pharmacodynamic consequences of drug interactions with oxycodone.

Methods The 12 participants (CYP2D6 extensive metabolizers) were pre-treated with placebo, ketoconazole or paroxetine before oral oxycodone ingestion $(0.2 \mathrm{mg} / \mathrm{kg})$.

Results Pre-treatment with ketoconazole increased the AUC for oxycodone 2- to 3-fold compared with placebo or paroxetine. In combination with placebo, oxycodone induced the expected decrease in pupil diameter. This decrease was accentuated in the presence of ketoconazole, but blunted by paroxetine. In comparison to pre-treatment with placebo, ketoconazole increased nausea, drowsiness, and pruritus associated with oxycodone. In contrast, the effect of pretreatment with paroxetine on the above-mentioned adverse events was not different from that of placebo. Ketoconazole increased the analgetic effect of oxycodone, whereas paroxetine was not different from placebo.
\end{abstract}

Oliver Kummer and Felix Hammann contributed equally to this work.

O. Kummer · F. Hammann · C. Moser · J. Drewe •

S. Krähenbühl $(\bowtie)$

Division of Clinical Pharmacology and Toxicology,

Department of Biomedicine, University Hospital,

4031 Basel, Switzerland

e-mail: kraehenbuehl@uhbs.ch

O. Schaller

Mundipharma Medical Company,

Basel, Switzerland
Conclusions Inhibition of CYP3A4 by ketoconazole increases the exposure and some pharmacodynamic effects of oxycodone. Paroxetine pretreatment inhibits CYP2D6 without inducing relevant changes in oxycodone exposure, and partially blunts the pharmacodynamic effects of oxycodone due to intrinsic pharmacological activities. Pharmacodynamic changes associated with CYP3A4 inhibition may be clinically important in patients treated with oxycodone.

Keywords Oxycodone $\cdot$ Ketoconazole $\cdot$ Paroxetine $\cdot$ Drug interactions $\cdot$ Pharmacokinetics $\cdot$ Pharmacodynamics

\section{Introduction}

Oxycodone (6-deoxy-7,8-dehydro-14-hydroxy-3-O-methyl6-oxymorphine) is a semi-synthetic opioid analgetic used frequently for the treatment of moderate to severe pain [1], including postoperative pain [2] or pain associated with cancer [3]. Despite having been developed more than 90 years ago as an alternative to heroine, some aspects of its pharmacodynamic characteristics and of its biotransformation have only recently been the subject of research or still remain unclear.

Oxycodone has an analgetic potency of approximately 2 relative to morphine $[4,5]$ and reveals affinity primarily for $\mu$-opioid receptors [1]. After oral administration, its bioavailability in humans is between 60 and $87 \%$ and its elimination half-life 3-5 h [1]. Oxycodone is heavily metabolized with less than $10 \%$ of the orally administered drug excreted unchanged in the urine [6]. 
Biotransformation occurs in the liver by different cytochrome P450 isoenzymes (CYP) [7]. Most of the drug is Ndemethylated by CYP3A4 to noroxycodone ( $5 \alpha-4,5$-epoxy14-hydroxy-3-methoxymorphinan-6-one) (Fig. 1). A smaller amount is O-demethylated by CYP2D6 to the active metabolite oxymorphone (4,5 $\alpha$-epoxy-3,14-dihydroxy-17methylmorphinan-6-one), exhibiting about 40 times the affinity and 8 times the potency on $\mu$-opioid receptors compared with the mother substance $[1,7]$. Oxymorphone itself is also marketed as an analgetic and is used primarily for cancer pain management and in obstetrics [8].

Considering the strong pharmacodynamic effects of oxymorphone, it is surprising that suppression of the production of oxymorphone through inhibition of CYP2D6 by quinidine did not substantially alter the pharmacodynamic effects of oral oxycodone [9]. This may be explained by the low plasma concentrations of oxymorphone reached in persons treated with oxycodone $[9,10]$. On the other hand, since oxycodone had more pronounced analgetic activity in CYP2D6 extensive compared with poor metabolizers under experimental conditions, the formation of oxymorphone may contribute to its analgetic activity in CYP2D6 extensive metabolizers [11]. This analgetic effect associated with CYP2D6 may not be clinically relevant; however, since the postoperative pain control by oxycodone was not significantly different between CYP2D6 poor and extensive metabolizers [12]. In contrast to oxymorphone, noroxycodone, quantitatively the most important metabolite of oxycodone, has only a low affinity for $\mu$-opioid receptors and a low analgetic potency [10]. In vitro, inhibition of CYP3A4 with ketoconazole reduced the formation of noroxycodone by $>90 \%$ [7]. Recent studies in humans have shown that inhibition of CYP3A4 by voriconazole [13] or telithromycin [14] increased exposure and the pharmacodynamic effects of oral oxycodone. Accordingly, CYP3A4 induction by rifampicin has recently been shown to decrease the exposure to intravenous or oral oxycodone and to attenuate its pharmacological effects [15].

Fig. 1 Oxycodone structure and metabolism. The main metabolic pathway of oxycodone is the formation of the pharmacologically inactive noroxycodone by CYP3A4

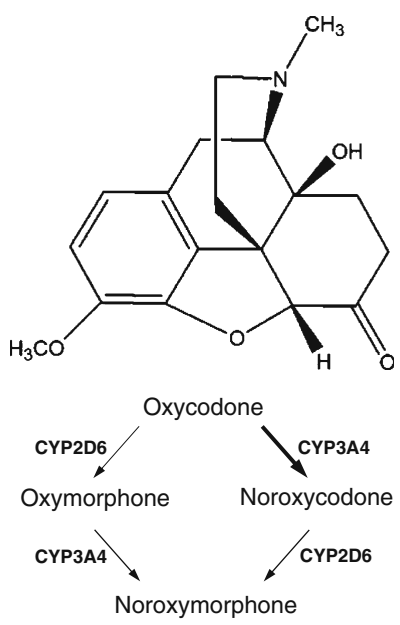

The aim of the study was to investigate the effects of CYP2D6 and CYP3A4 inhibition on oxycodone kinetics and dynamics in the same individuals. For this purpose, we used the SSRI paroxetine as a CYP2D6 [16] and ketoconazole as a CYP3A4 inhibitor [7]. Regarding the study aim, it is important to realize that the clinical part of the study had been planned and conducted before the studies describing the effect of CYP3A4 inhibitors [13, 14] or inducers [15] were published.

\section{Materials and methods}

Study subjects

The 14 subjects selected for the study had to be nonsmokers aged between 18 and 50 years (median age \pm standard deviation $25 \pm 7$ years, range 21 to 41 years) and CYP2D6 extensive metabolizers. They all had a normal physical examination, normal blood pressure, body weight within $15 \%$ of ideal (weight $72 \pm 7 \mathrm{~kg}$, height $181 \pm 5 \mathrm{~cm}$, body mass index $22 \pm 2 \mathrm{~kg} / \mathrm{m}^{2}$ ), normal electrocardiogram and normal routine blood chemistry. They had to abstain from ingestion of drugs (including herbal drugs), grapefruit juice, and beverages containing caffeine during the whole study period. For CYP2D6 genotyping, an EDTA blood sample was obtained from which genomic DNA was extracted using the Promega DNA purification kit (Dübendorf, Switzerland). The DNA was analyzed for CYP2D6 polymorphisms and gene duplications using real-time PCR, as described by Müller et al. [17]. Only probands with the $* 1 / * 1$ genotype were included in the study. They were all extensive metabolizers as assessed using dextrometorphan as a probe drug [18]. A drug screen in the urine was performed to identify and exclude active drug users.

Drugs used in the study

Oxycodone was obtained as an oral solution with a dosing syringe (OxyNorm ${ }^{\circledR}, 10 \mathrm{mg} / \mathrm{ml}$ ) from Mundipharma (Basel, Switzerland). Ketoconazole was purchased as 200mg tablets (Nizoral ${ }^{\circledR}$ ) from Janssen-Cilag (Baar, Switzerland) and paroxetine as 20-mg tablets (Deroxat ${ }^{\circledR}$ ) from GlaxoSmithKline (Münchenbuchsee, Switzerland). To ensure blinding, the tablets were filled into capsules; identical capsules containing only lactose served as placebo. All the capsules used were prepared by the local hospital pharmacy.

Study design

The study was conducted according the principles of the declaration of Helsinki, was approved by the Ethics Committee of the State of Basel, and was notified by the 
Swiss Drug Regulatory Agency (Swissmedic). The selected volunteers had to understand the design of the study and to give written informed consent before undergoing any study-related procedures. The study was designed as a randomized, double-blind, three-way cross-over, singlecenter trial that was performed at the Phase I Study Center of the University Hospital Basel. The study endpoints were the effect of ketoconazole and paroxetine on the area under the plasma concentration-time curve (AUC) and on the pharmacodynamic variables (see below) of oxycodone.

Subjects were randomized to one of the three doubleblinded pretreatments (placebo, ketoconazole $200 \mathrm{mg}$ or paroxetine $20 \mathrm{mg}$ ), which had to be ingested $48 \mathrm{~h}, 24 \mathrm{~h}$, and $1 \mathrm{~h}$ before oral ingestion of oxycodone $(0.2 \mathrm{mg} / \mathrm{kg}$ body weight). Subjects had to stay within the study center for the first $14 \mathrm{~h}$ after ingestion of oxycodone. A light breakfast was served after the administration of oxycodone and a light meal at $5 \mathrm{~h}$. The intake of alcohol and/or xanthinecontaining food and/or beverages as well as grapefruit and/ or grapefruit juice was not allowed from $48 \mathrm{~h}$ before till $48 \mathrm{~h}$ after oxycodone ingestion.

Before and 0.5, 1, 1.5, 2, 2.5, 3, 3.5, 4, 5, 6, 8, 10, 12, 24, 36 , and $48 \mathrm{~h}$ after ingestion of oxycodone, $7.5 \mathrm{ml}$ of blood was withdrawn through a catheter placed in a vein of the forearm into heparin-coated tubes. Plasma was separated and stored at $-70^{\circ} \mathrm{C}$ pending analysis. Subjects underwent static and dynamic pupil assessments, cold pressor tests, and VAS-based recordings of subjective effects pre-dose as well as 2, 4, 6, 8, and $12 \mathrm{~h}$ post-dose. At $12 \mathrm{~h}$ post-dose, subjects were discharged from the Study Center and returned the following days for the final blood samplings. A wash-out period of 14 days followed the treatment phases.

Quantification and pharmacokinetics of oxycodone, noroxycodone, and oxymorphone

Plasma concentrations of oxycodone and its two major metabolites were determined by LC-MS, as described by Neuvonen et al. [19]. The LOQs of the method were $0.1 \mathrm{ng} /$ $\mathrm{mL}$ for oxycodone and $0.25 \mathrm{ng} / \mathrm{mL}$ for oxymorphone and noroxycodone. The standard curves were linear up to $50 \mathrm{ng} / \mathrm{mL}$. The inter- and intra-day precisions were $<15 \%$ at low $(0.5 \mathrm{ng} / \mathrm{mL})$ and high concentrations $(50 \mathrm{ng} / \mathrm{mL})$ of oxycodone and its metabolites.

The pharmacokinetic variables of oxycodone were either obtained directly from the individual plasma concentrations $\left(\mathrm{C}_{\max }\right.$ and $\left.\mathrm{t}_{\max }\right)$ or calculated with non-compartmental analysis using WinNonlin (Pharsight Corporation, Mountain View, CA, USA; $\mathrm{AUC}_{0-\mathrm{t}}, \mathrm{AUC}_{t-\infty}, \lambda_{\mathrm{z}}$ and $\mathrm{t}_{1 / 2}$ ), as described previously [20].

For noroxycodone and oxymorphone, only the $\mathrm{C}_{\max }$ values are provided, which were obtained from the rough data as described above for oxycodone.
Static and dynamic pupillometry

Subjects were examined with a desktop pupillometer, the Compact Integrated Pupillograph (CIP; Amtech, Hamburg, Germany). This system uses an infrared camera to monitor a subject's eye, generates a gray-scale image of it, and computes a luminosity histogram over a line crossing the equator of the image. A separate room was furnished for this test with constant lighting conditions and reduced ambient noise. Subjects were asked, after a 5 -min period of rest inside the room, to place their head onto the head rest of the apparatus and to stare into the distance so as to eliminate the miosis that accompanies the accommodation reflex. After having put the subject's eye into focus, a light stimulus of $250 \mathrm{~ms}$ was applied, inducing the pupillary light reflex, which was recorded using the integrated software. Four measurements of good quality were obtained for each session with $30 \mathrm{~s}$ relaxation time for dark adaptation between the runs.

The plotted raw data still contained low amplitude system noise from the individual measurements. To correct for these, a Savitzky-Golay nine-point smoothing algorithm [21] was implemented in Excel, ultimately yielding a single smooth curve representing the pupillodynamics of one time point (Fig. 2). The following parameters were extracted from the smoothed median curves: initial diameter of the pupil, latency until first light reaction of the pupil, amplitude of the light reaction, time to maximal constriction of the pupil, and the time to one-third redilatation.

\section{Analgesia}

Cold pressor testing was used to measure pain tolerability $[10,22]$. A water receptacle was filled with cold water and

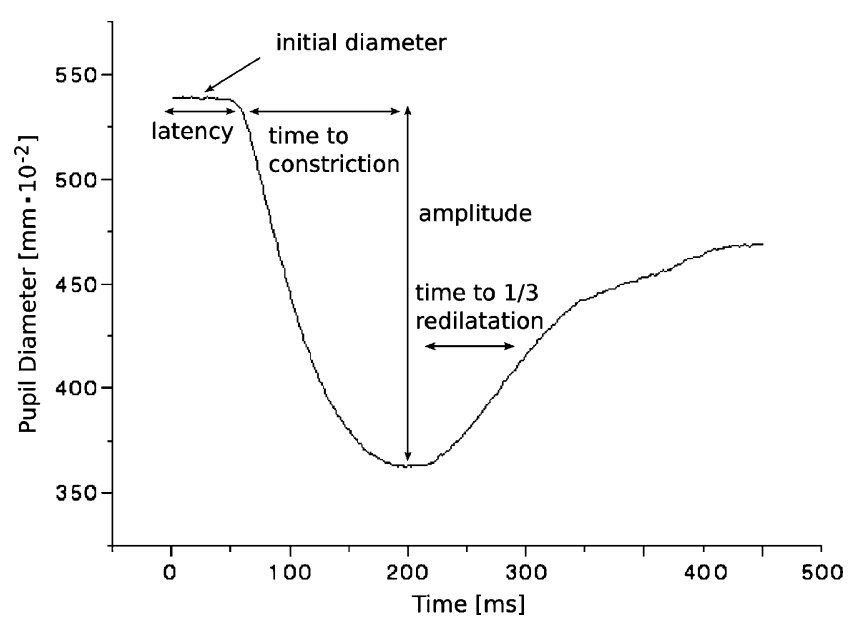

Fig. 2 Dynamic pupillometry. Subjects were studied under constant lighting conditions and reduced ambient noise. A light stimulus of $250 \mathrm{~ms}$ was applied, inducing the pupillary light reflex, which was recorded and evaluated as described in the figure and in Materials and methods 
crushed ice and stirred until a temperature of $1 \pm 0.5^{\circ} \mathrm{C}$ was achieved. Subjects placed their non-dominant hand in the water bath with fingers spread and were told to retract the hand only when the pain became intolerable. A 15-min time limit was set for safety reasons; for subjects not withdrawing within this time, 15 min was recorded.

\section{Adverse events}

Four of the most often observed adverse events associated with opioids (nausea, drowsiness, pruritus, euphoria) were monitored using a visual analog scale (line length $100 \mathrm{~mm}$; $0 \mathrm{~mm}$ "not at all," $100 \mathrm{~mm}$ "extremely strong"). Scores were measured in millimeters and evaluated as deviations from baseline $(0 \mathrm{~mm})$. Other possible adverse events were asked for and recorded, but not quantified.

\section{Calculations and statistics}

Maximal effects $\left(E_{\max }\right)$ for dynamic pupillometry, adverse events of oxycodone and the cold pressor test were obtained from the raw data as the difference from the basal value obtained at time 0 before the application of oxycodone. Areas under the effect curve (AUECs) were calculated using the trapezoidal rule. The areas were calculated using the value at time 0 (before the application of oxycodone) as the basis. The areas reflecting the pharmacodynamic effect of oxycodone were marked with a positive prefix.

Statistical evaluations were performed with SigmaStat 3.5 software (Scientific Solutions, Pully Lausanne, Switzerland). Multiple group means were compared by one-way analysis of variance. In the case of significance, differences between the individual treatments were assessed using the Sidak-Holm test. Repeated measures (see Figs. 4 and 5) were analyzed using a one-way repeated measures analysis of variance followed by Tukey's test. The difference between the values in patients pretreated with placebo vs 0 for the parameters drowsiness, euphoria, pruritus, and nausea (see Table 3 ) was tested using a $t$ test. All tests were used as two-sided tests. The level of significance was set to $p=0.05$. Data are presented as mean $\pm \mathrm{SD}$ except for the figures, where mean \pm SEM are given.

\section{Results}

Pharmacokinetics of oxycodone and oxycodone metabolites

The kinetic parameters obtained for oxycodone under the different pre-treatments are given in Fig. 3 and Table 1. Compared with placebo, pre-treatment with paroxetine did not significantly affect the kinetics of oxycodone. In

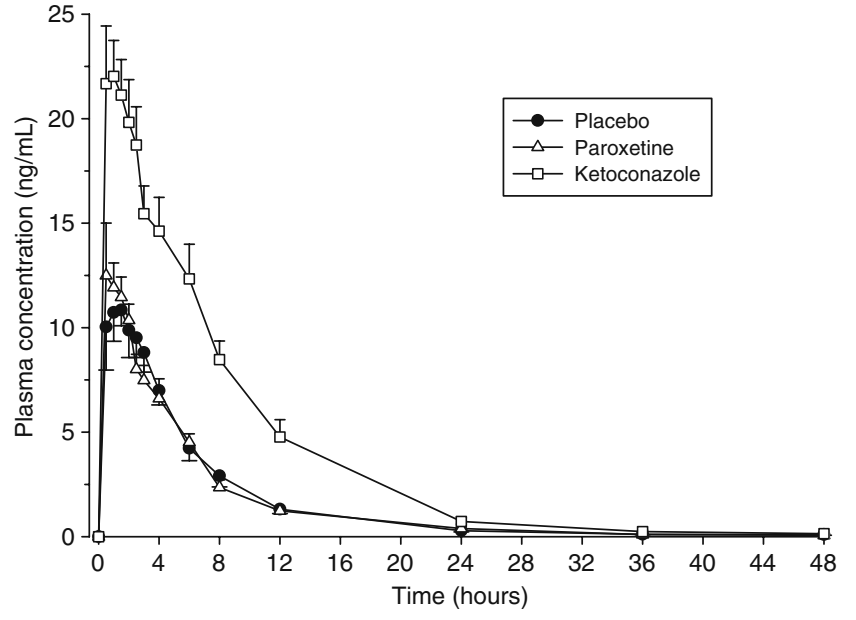

Fig. 3 Pharmacokinetics of oxycodone. Subjects were pre-treated with placebo, paroxetine or ketoconazole before ingesting a single oral dose of oxycodone $(0.2 \mathrm{mg} / \mathrm{kg}$ body weight $)$. Ketoconazole increased the exposure to oxycodone, whereas the effect of paroxetine was not different from that of placebo

contrast, pre-treatment with ketoconazole was associated with a higher $\mathrm{C}_{\max }$ (increase by $77 \%$ ) and AUC (increase by $146 \%$ ) of oxycodone compared with placebo, demonstrating the importance of CYP3A4 in oxycodone metabolism. In contrast, the half-life of oxycodone was not affected by any of the pre-treatments.

Compared with placebo, pretreatment with ketoconazole was associated with a decrease in $\mathrm{C}_{\max }$ for noroxycodone $(5.41 \pm 0.72$ vs $9.83 \pm 0.43 \mathrm{ng} / \mathrm{mL}, p<0.05)$, but had no effect on the $\mathrm{C}_{\max }$ of oxymorphone $(0.81 \pm 0.06$ vs $0.71 \pm$ $0.07 \mathrm{ng} / \mathrm{mL}$ ). In contrast, in comparison to placebo, pretreatment with paroxetine was associated with a decrease in the $\mathrm{C}_{\max }$ of oxymorphone $(0.44 \pm 0.02$ vs $0.71 \pm$ $0.07 \mathrm{ng} / \mathrm{mL}, p<0.05)$, but had no effect on the $\mathrm{C}_{\max }$ of noroxycodone $(9.32 \pm 0.52$ vs $9.83 \pm 0.43 \mathrm{ng} / \mathrm{mL})$.

\section{Effect of oxycodone on pupillometry}

Pre-treatment with ketoconazole or paroxetine in the absence of oxycodone had no significant effect on any of the variables determined (pupil diameter, time to maximal constriction, pupil amplitude, and pupil redilatation time; Fig. 4). As expected, treatment with oxycodone alone affected all variables assessed (see placebo in Table 2, Fig. 4). These effects of oxycodone were maximal at the 2$\mathrm{h}$ time point (Fig. 4). Since no earlier time points have been assessed (this is true for all pharmacodynamic measurements), it is possible that the maximal pharmacodynamic effect of oxycodone has been missed. In comparison to placebo, pre-treatment with ketoconazole was associated with a more accentuated and a longer lasting contraction of 
Table 1 Pharmacokinetic parameters of oral oxycodone $(0.2 \mathrm{mg} / \mathrm{kg}$ body weight $)$ in healthy volunteers $(n=12)$ pre-treated with placebo, three doses of paroxetine (20 mg per dose) or ketoconazole (200 mg per dose). Data are given as mean $\pm \mathrm{SD}$

\begin{tabular}{lccc}
\hline Parameter & Placebo & Paroxetine & Ketoconazole \\
\hline $\mathrm{C}_{\text {max }}(\mathrm{ng} / \mathrm{mL})$ & $15.0 \pm 4.5$ & $15.1 \pm 7.3$ & $26.5 \pm 5.5^{\mathrm{a}}$ \\
$\mathrm{T}_{\text {max }}(\mathrm{h})$ & $1.25 \pm .80$ & $1.00 \pm 0.42$ & $1.04 \pm 0.89$ \\
Elimination rate constant $\lambda_{\mathrm{z}}\left(\mathrm{h}^{-1}\right)$ & $0.109 \pm 0.017$ & $0.112 \pm 0.014$ & $0.119 \pm 0.014$ \\
$\mathrm{t}^{1} / 2(\mathrm{~h})$ & $6.62 \pm 1.59$ & $6.32 \pm 0.90$ & $5.89 \pm 0.69$ \\
$\mathrm{AUC}_{0-48 \mathrm{~h}}\left(\mathrm{ng} \times \mathrm{mL}^{-1} \times \mathrm{h}\right)$ & $75.6 \pm 25.3$ & $75.0 \pm 26.7$ & $186 \pm 69^{\mathrm{a}, \mathrm{b}}$ \\
$\mathrm{AUC}_{0-\infty}\left(\mathrm{ng} \times \mathrm{mL}^{-1} \times \mathrm{h}\right)$ & $76.8 \pm 25.3$ & $75.6 \pm 26.7$ & $187 \pm 69^{\mathrm{a}, \mathrm{b}}$ \\
\hline
\end{tabular}

${ }^{\mathrm{a}} p<0.05$ vs paroxetine

${ }^{\mathrm{b}} p<0.05$ vs placebo

the pupil (Table 2, Fig. 4a-c) and also with a shorter and longer lasting shortening of the redilatation time (Table 2, Fig. 4d). In contrast to ketoconazole, pre-treatment with paroxetine was associated with a block of the effects of oxycodone on pupil diameter and amplitude as well as time to maximal constriction and velocity of pupil redilatation (Table 2, Fig. 4).

\section{Effect on cold pressor test}

Treatment with oxycodone was associated with a significant prolongation of the immersion period at $2 \mathrm{~h}$ after ingestion of oxycodone (Fig. 5). Pre-treatment with ketoconazole accentuated the analgetic effect of oxycodone, leading to an increase in the immersion period starting at $2 \mathrm{~h}$ and lasting up to $6 \mathrm{~h}$ after ingestion of oxycodone. In contrast, pre-treatment with paroxetine prevented the analgetic activity of oxycodone. The corresponding values for the area under the effect curve (AUEC) were (mean $\pm \mathrm{SD}$ ) $512 \pm 324$ for placebo ( $p<0.05$ vs paroxetine), $208 \pm 192$ for paroxetine and $1,046 \pm 1,199 \mathrm{~s} \times \mathrm{h}$ for ketoconazole $(p<0.05$ vs paroxetine) pretreatment. The values for the maximal effect $\left(E_{\max }\right)$ were $162 \pm 221$ for placebo, $54 \pm 34$ for paroxetine and $220 \pm 226$ s for ketoconazole ( $p<0.05$ vs paroxetine) pretreatment.

\section{Adverse events}

No severe adverse events were reported by the study subjects. Four events were specifically recorded, drowsiness, euphoria, pruritus, and nausea. Compared with zero (no effect), $E_{\max }$ was increased for drowsiness and euphoria, and AUEC for drowsiness for pretreatment with placebo (Table 3). Pre-treatment with ketoconazole accentuated the effect of oxycodone on drowsiness and was associated with nausea and pruritus, but did not affect the effect of oxycodone on euphoria (Table 3). In comparison, pre-treatment with paroxetine was not significantly different from placebo (Table 3 ).

\section{Discussion}

Our study shows that inhibition of CYP3A4 by ketoconazole increases the exposure to oral oxycodone as well as many of its pharmacodynamic effects. In contrast, inhibition of CYP2D6 by paroxetine did not increase oxycodone exposure, but attenuated some of the pharmacodynamic effects of oxycodone.

Regarding the effect of reduced CYP2D6 activity on oxycodone metabolism and action, the results of our study are in agreement with those of Heiskanen et al. and Grönlund et al. in healthy volunteers [9, 23] and those of Lemberg et al. and Zwisler et al. in patients treated with oxycodone $[12,24]$. These studies showed that patients or probands with inhibited CYP2D6 [9, 23, 24] or CYP2D6 slow metabolizers [12] have decreased formation of oxymorphone with or without only a small increase in oxycodone exposure and there is no significant effect on the analgetic activity of oxycodone. In a second study, in which Zwisler et al. investigated the kinetics and dynamics of oxycodone in healthy CYP2D6 extensive and poor metabolizers [11], the observed changes in oxycodone kinetics were also associated with dynamic changes. In this study, the analgetic effect of oxycodone was more accentuated in CYP2D6 extensive compared with poor metabolizers, suggesting an analgetic effect of oxymorphone. Taking into consideration all currently available studies on this subject, however, the available data indicate that impaired activity of CYP2D6 (by administration of CYP2D6 inhibitors or by enzyme polymorphisms) is associated with only small changes in oxycodone pharmacokinetics, which do not usually result in altered oxycodone pharmacodynamics. 

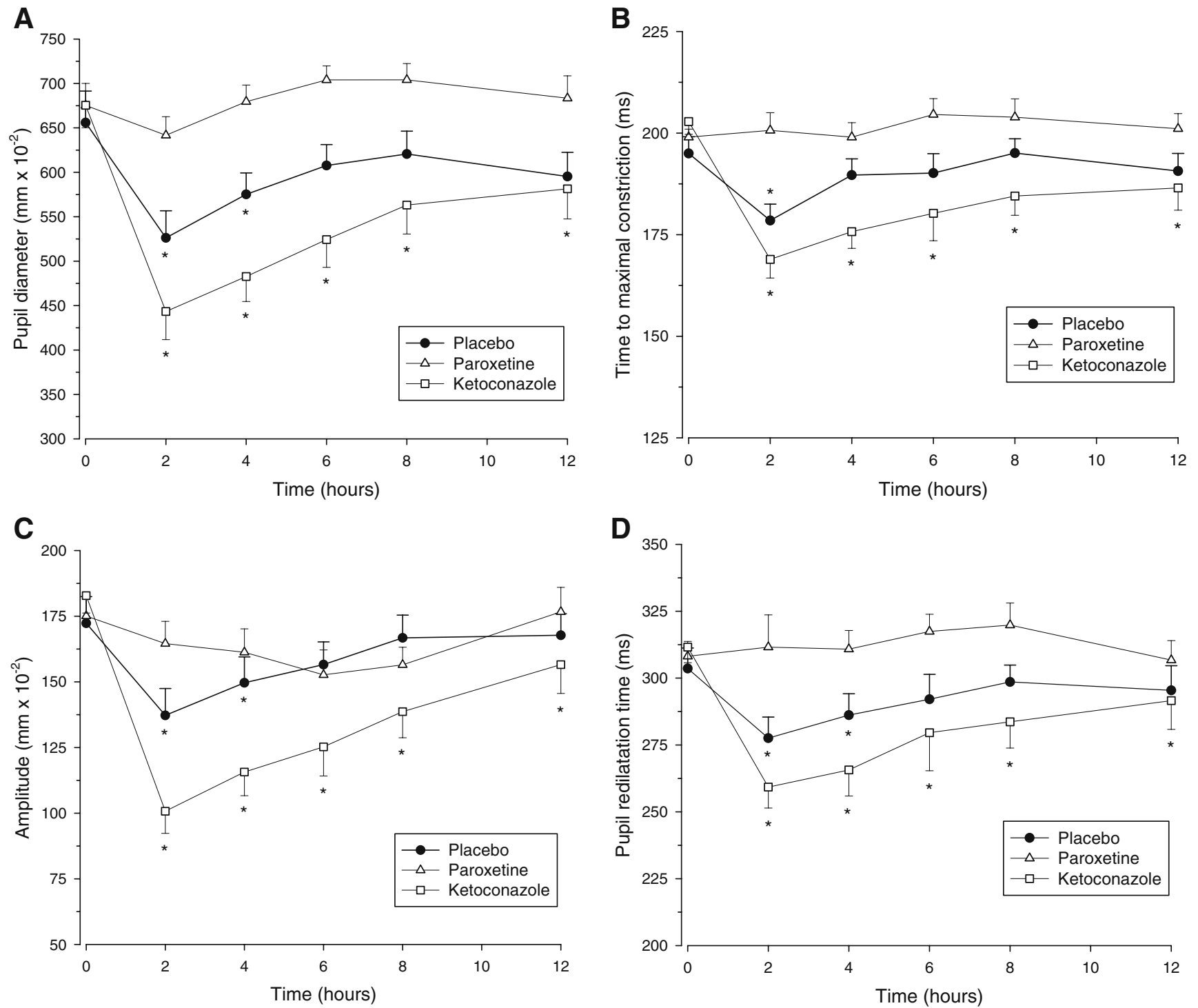

Fig. 4 Pupillometric assessment. The data were obtained using a desktop pupillometer (Compact Integrated Pupillograph; Amtech, Hamburg, Germany) as described in Materials and methods. The

pupillary reflex was induced by a light stimulus of $250 \mathrm{~ms} . n=12$ subjects, results presented as mean \pm SEM

In our study, changes in oxycodone pharmacodynamics associated with CYP2D6 inhibition cannot be judged, because the pharmacodynamic effects of paroxetine interfered with those of oxycodone. While pre-treatment with paroxetine revealed no significant effect on pupil diameter, it blunted the effects of oxycodone on the pupil. In other studies, SSRIs such as fluoxetine, citalopram or paroxetine have been described to increase pupil diameter [25-27]. To the best of our knowledge, the effects of SSRIs on pupil reaction associated with opioids have so far not been described. The miotic reaction of opioids is believed to be mediated by the parasympathetic nervous system [28, 29], most probably by stimulation of preganglionic cholinergic neurons in the Edinger-Westphal nucleus [30]. On the other hand, the effects of SSRIs on pupil reaction is considered to be mediated by serotoninergic stimulation of central $5 \mathrm{HT}_{1 \mathrm{~A}}$ receptors, which is associated with synaptic release of noradrenalin followed by stimulation of postsynaptic alpha2-adrenoreceptors [27, 31]. Stimulation of alpha2adrenoreceptors in the Edinger-Westphal nucleus counteracts cholinergic stimulation associated with opioids [31] and can therefore explain the blunted pupillary reaction of oxycodone after pre-treatment with paroxetine. This finding may be of clinical importance, since patients treated with opioids may have normally sized, unreactive pupils when they are concomitantly treated with an SSRI. 
Table 2 Dynamic pupillometry. The papillary reflex was induced by a light stimulus of $250 \mathrm{~ms}$ using a desktop pupillometer (Compact Integrated Pupillograph; Amtech, Hamburg, Germany) as described in Materials and methods. The pharmacological effect of oxycodone always has a positive prefix. $n=12$ subjects, results presented as mean \pm SD
${ }^{\mathrm{a}} p<0.05$ vs placebo
${ }^{\mathrm{b}} p<0.05$ vs paroxetine

\begin{tabular}{lccc}
\hline Parameter & Placebo & Paroxetine & Ketoconazole \\
\hline Pupil diameter & & & \\
$-\mathrm{E}_{\max }\left(\mathrm{mm} \times 10^{-2}\right)$ & $144 \pm 97$ & $49 \pm 55^{\mathrm{a}}$ & $235 \pm 76^{\mathrm{a}, \mathrm{b}}$ \\
- AUEC $\left(\mathrm{mm} \times 10^{-2} \times \mathrm{h}\right)$ & $744 \pm 987$ & $-101 \pm 682^{\mathrm{a}}$ & $1,680 \pm 760^{\mathrm{a}, \mathrm{b}}$ \\
Latency of pupil reaction & & & \\
$-\mathrm{E}_{\max }(\mathrm{ms})$ & $4.3 \pm 4.5$ & $4.9 \pm 4.2$ & $6.7 \pm 3.5$ \\
- AUEC $(\mathrm{ms} \times \mathrm{h})$ & $17.9 \pm 44.7$ & $18.7 \pm 60.6$ & $41.1 \pm 43.3$ \\
Amplitude of pupil reaction & & & \\
$-\mathrm{E}_{\max }\left(\mathrm{mm} \times 10^{-2}\right)$ & $41.3 \pm 31.9$ & $33.8 \pm 21.5$ & $53.9 \pm 32.2^{\mathrm{a}, \mathrm{b}}$ \\
- AUEC $\left(\mathrm{mm} \times 10^{-2} \times \mathrm{h}\right)$ & $173 \pm 322$ & $146 \pm 239$ & \\
Time to pupil constriction & & & $38.3 \pm 15.9^{\mathrm{a}, \mathrm{b}}$ \\
$-\mathrm{E}_{\max }(\mathrm{ms})$ & $20.9 \pm 16.3$ & $10.6 \pm 10.7$ & $255 \pm 135^{\mathrm{a}, \mathrm{b}}$ \\
- AUEC $(\mathrm{ms} \times \mathrm{h})$ & $62 \pm 157$ & $-33 \pm 155$ & $61.5 \pm 23.2^{\mathrm{a}, \mathrm{b}}$ \\
Pupil redilatation & & & $384 \pm 256^{\mathrm{b}}$ \\
$-\mathrm{E}_{\max }(\mathrm{ms})$ & $37.1 \pm 24.2$ & $17.9 \pm 21.5$ & $-63 \pm 230$ \\
- AUEC $\left(\mathrm{ms}{ }^{2}\right)$ & $141 \pm 291$ & & \\
\hline
\end{tabular}

Effects of SSRIs on pain and/or possible interferences with opioids have so far been reported in only a few studies. While SSRIs such as fluoxetine and paroxetine have been found to exhibit analgetic properties in mice [32-34], fluoxetine itself revealed no analgetic properties in humans [35]. When combined with morphine, the analgetic effect of morphine was marginally improved by fluoxetine in the study by Erjavec et al. [35], but decreased in another study [36]. In comparison, in our study, paroxetine blunted the effect of oxycodone on the cold pressor test. Further studies are necessary to be able to draw firm conclusions

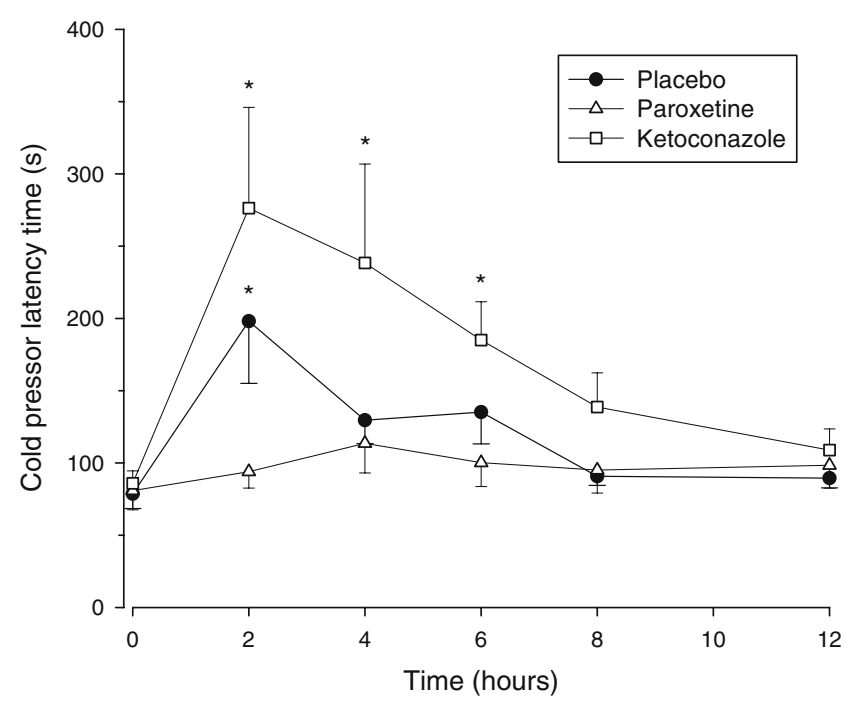

Fig. 5 Analgetic effect of oxycodone. The cold pressor test was used to measure pain tolerability as described in Materials and methods. $n=$ 12 subjects, results presented as mean \pm SEM. $* p<0.05$ vs latency time at $\mathrm{t}=0$ within the same treatment group about possible interferences between SSRIs and the pharmacodynamic effects of opioids.

Regarding the effect of CYP3A4 inhibition, our findings are in good agreement with those of Hagelberg et al. [13], who demonstrated that CYP3A4 inhibition by voriconazole increases exposure to and the dynamic effects of oxycodone. In comparison to the study by Hagelberg et al. [13], who described a 2.7- to 5.6-fold increase in the AUC of oxycodone after pre-treatment with voriconazole, the effect of ketoconazole on oxycodone exposure was slightly less

Table 3 Adverse events of oxycodone after different pre-treatments. Adverse events were recorded using visual analog scales (0 to $100 \mathrm{~mm}$ ). The pharmacological effect of oxycodone has always a positive prefix. $n=12$ subjects, results presented as mean \pm SEM

\begin{tabular}{lccc}
\hline Parameter & Placebo & Paroxetine & Ketoconazole \\
\hline Drowsiness & & & \\
$-\mathrm{E}_{\max }(\mathrm{mm})$ & $44.4 \pm 30.1^{\mathrm{a}}$ & $29.2 \pm 24.9$ & $53.7 \pm 23.9$ \\
$-\mathrm{AUEC}(\mathrm{mm} \times \mathrm{h})$ & $171 \pm 260^{\mathrm{a}}$ & $39 \pm 200$ & $309 \pm 198^{\mathrm{b}}$ \\
Euphoria & & & \\
$-\mathrm{E}_{\max }(\mathrm{mm})$ & $14.8 \pm 13.5^{\mathrm{a}}$ & $14.4 \pm 13.9$ & $7.7 \pm 10.0$ \\
$-\mathrm{AUEC}(\mathrm{mm} \times \mathrm{h})$ & $74 \pm 169$ & $67 \pm 141$ & $-39 \pm 112$ \\
Pruritus & & & \\
$-\mathrm{E}_{\max }(\mathrm{mm})$ & $0.7 \pm 1.4$ & $4.3 \pm 10.4$ & $17.7 \pm 22.9^{\mathrm{c}}$ \\
- AUEC $(\mathrm{mm} \times \mathrm{h})$ & $-19.3 \pm 75.5$ & $13.1 \pm 31.2$ & $52 \pm 122$ \\
Nausea & & & \\
$-\mathrm{E}_{\max }(\mathrm{mm})$ & $9.2 \pm 24.6$ & $17.1 \pm 28.8$ & $36.8 \pm 42.3$ \\
- AUEC $(\mathrm{mm} \times \mathrm{h})$ & $36.3 \pm 97.0$ & $14.0 \pm 23.6$ & $144 \pm 166^{\mathrm{b}, \mathrm{c}}$ \\
\hline
\end{tabular}

${ }^{\mathrm{a}} p<0.05$ placebo vs zero

${ }^{\mathrm{b}} p<0.05$ vs paroxetine

${ }^{\mathrm{c}} p<0.05$ vs placebo 
accentuated in our study (2.4-fold increase in AUC and 1.8fold increase in $\mathrm{C}_{\max }$ ). Nevertheless, similar to the findings by Hagelberg et al. [13], the observed increase in oxycodone exposure was associated with pharmacodynamic changes, in particular concerning pupillometry. The results of our study also agree with statements made by Lalovic et al. [10], namely that CYP3A4-mediated N-demethylation is quantitatively the most important metabolic pathway of oxycodone and that the analgetic activity of oxycodone is primarily associated with the mother substance. As shown by Zwisler et al., a significant contribution of oxymorphone can be demonstrated in extensive CYP2D6 metabolizers under experimental [11], but not under clinical conditions [12].

Based on the current and previous studies [13-15], drug interactions with oxycodone can be expected to have clinical consequences. Inhibition of CYP3A4 increases the exposure to oxycodone 2- to 5-fold and must therefore be taken into account in patients treated with this drug. Similarly, induction of CYP3A4 can be expected to be associated with a decrease in the analgetic effect of oxycodone. This is also the case for other opioids that are primarily metabolized by CYP3A4, such as methadone [37], fentanyl [38], and buprenorphine [39]. Regarding the high inter-individual variability of CYP3A4 activity [40, 41], it is important to start oxycodone and the other opioids primarily metabolized by CYP3A4 at a low dosage and to perform a careful up-titration, until sufficient analgesia is obtained. While CYP2D6 inhibition does not significantly affect the kinetics and dynamics of oxycodone (this study and [9]) and oxycodone is also effective and safe in CYP2D6 poor metabolizers $[11,12]$, there are so far no data on the efficacy and safety of oxycodone in ultra-rapid CYP2D6 metabolizers. CYP2D6 ultra-rapid metabolizers should be up-titrated very carefully with oxycodone to avoid adverse reactions due to increased formation of the active metabolite oxymorphone. Such reactions have been described for CYP2D6 ultra-rapid metabolizers treated with codeine [42, 43] or tramadol [44].

In conclusion, inhibition of CYP3A4 by ketoconazole increases the exposure to and the pharmacodynamic effects of oxycodone. Inhibition of CYP2D6 by paroxetine does not significantly increase oxycodone exposure, but influences oxycodone pharmacodynamics through its own pharmacodynamic activity. Paroxetine is therefore not an ideal CYP2D6 inhibitor for studies in which the central effects of drugs are important variables. Pharmacokinetic and dynamic changes associated with CYP3A4 inhibition may be clinically important in patients treated with oxycodone.

Acknowledgements This study was funded by the Division of Clinical Pharmacology \& Toxicology, University Hospital Basel, Switzerland, and by Mundipharma Medical Company. We thank Natalie Grignaschi and Beatrice Vetter for the determination of oxycodone.

\section{References}

1. Davis MP, Varga J, Dickerson D, Walsh D, LeGrand SB, Lagman R (2003) Normal-release and controlled-release oxycodone: pharmacokinetics, pharmacodynamics, and controversy. Support Care Cancer 11:84-92

2. Nuutinen LS, Wuolijoki E, Pentikainen IT (1986) Diclofenac and oxycodone in treatment of postoperative pain: a double-blind trial. Acta Anaesthesiol Scand 30:620-624

3. Parris WC, Johnson BW Jr, Croghan MK et al (1998) The use of controlled-release oxycodone for the treatment of chronic cancer pain: a randomized, double-blind study. J Pain Symptom Manage $16: 205-211$

4. Bruera E, Belzile M, Pituskin E et al (1998) Randomized, doubleblind, cross-over trial comparing safety and efficacy of oral controlled-release oxycodone with controlled-release morphine in patients with cancer pain. J Clin Oncol 16:3222-3229

5. Curtis GB, Johnson GH, Clark P et al (1999) Relative potency of controlled-release oxycodone and controlled-release morphine in a postoperative pain model. Eur J Clin Pharmacol 55:425-429

6. Kirvela M, Lindgren L, Seppala T, Olkkola KT (1996) The pharmacokinetics of oxycodone in uremic patients undergoing renal transplantation. J Clin Anesth 8:13-18

7. Lalovic B, Phillips B, Risler LL, Howald W, Shen DD (2004) Quantitative contribution of CYP2D6 and CYP3A to oxycodone metabolism in human liver and intestinal microsomes. Drug Metab Dispos 32:447-454

8. Inturrisi CE (2002) Clinical pharmacology of opioids for pain. Clin J Pain 18:S3-S13

9. Heiskanen T, Olkkola KT, Kalso E (1998) Effects of blocking CYP2D6 on the pharmacokinetics and pharmacodynamics of oxycodone. Clin Pharmacol Ther 64:603-611

10. Lalovic B, Kharasch E, Hoffer C, Risler L, Liu-Chen LY, Shen DD (2006) Pharmacokinetics and pharmacodynamics of oral oxycodone in healthy human subjects: role of circulating active metabolites. Clin Pharmacol Ther 79:461-479

11. Zwisler ST, Enggaard TP, Noehr-Jensen L et al (2009) The hypoalgesic effect of oxycodone in human experimental pain models in relation to the CYP2D6 oxidation polymorphism. Basic Clin Pharmacol Toxicol 104:335-344

12. Zwisler ST, Enggaard TP, Mikkelsen S, Brosen K, Sindrup SH (2010) Impact of the CYP2D6 genotype on post-operative intravenous oxycodone analgesia. Acta Anaesthesiol Scand 54:232-240

13. Hagelberg NM, Nieminen TH, Saari TI, Neuvonen M, Neuvonen PJ, Laine K, Olkkola KT (2009) Voriconazole drastically increases exposure to oral oxycodone. Eur J Clin Pharmacol 65:263-271

14. Gronlund J, Saari T, Hagelberg N, Martikainen IK, Neuvonen PJ, Olkkola KT, Laine K (2010) Effect of telithromycin on the pharmacokinetics and pharmacodynamics of oral oxycodone. J Clin Pharmacol 50:101-108

15. Nieminen TH, Hagelberg NM, Saari TI et al (2009) Rifampin greatly reduces the plasma concentrations of intravenous and oral oxycodone. Anesthesiology 110:1371-1378

16. Laugesen S, Enggaard TP, Pedersen RS, Sindrup SH, Brosen K (2005) Paroxetine, a cytochrome P450 2D6 inhibitor, diminishes the stereoselective O-demethylation and reduces the hypoalgesic effect of tramadol. Clin Pharmacol Ther 77:312-323

17. Müller B, Zopf K, Bachofer J, Steimer W (2003) Optimized strategy for rapid cytochrome P450 2D6 genotyping by real-time long PCR. Clin Chem 49:1624-1631

18. Wenk M, Todesco L, Krahenbuhl S (2004) Effect of St John's wort on the activities of CYP1A2, CYP3A4, CYP2D6, Nacetyltransferase 2, and xanthine oxidase in healthy males and females. Br J Clin Pharmacol 57:495-499 
19. Neuvonen M, Neuvonen PJ (2008) Determination of oxycodone, noroxycodone, oxymorphone, and noroxymorphone in human plasma by liquid chromatography-electrospray-tandem mass spectrometry. Ther Drug Monit 30:333-340

20. Haegeli L, Brunner-La Rocca HP, Wenk M, Pfisterer M, Drewe J, Krahenbuhl S (2007) Sublingual administration of furosemide: new application of an old drug. Br J Clin Pharmacol 64:804-809

21. Savitzky A, Golay MJE (2002) Smoothing and differentiation of data by simplified least squares procedures. Anal Chem 36:1627-1639

22. Eisenberg E, Cohen D, Lawental E, Pud D (2007) Personality traits and sensitivity to pain in male chronic opioid addicts. $\mathrm{J}$ Opioid Manag 3:225-230

23. Grönlund J, Saari TI, Hagelberg NM, Neuvonen PJ, Olkkola KT, Laine K (2010) Exposure to oral oxycodone is increased by concomitant inhibition of CYP2D6 and 3A4 pathways, but not by inhibition of CYP2D6 alone. Br J Clin Pharmacol 70:78-87

24. Lemberg KK, Heiskanen TE, Neuvonen M, Kontinen VK, Neuvonen PJ, Dahl ML, Kalso EA (2010) Does coadministration of paroxetine change oxycodone analgesia: an interaction study in chronic pain patients. Scand J Pain 1:24-33

25. Johnson AM (1989) An overview of the animal pharmacology of paroxetine. Acta Psychiatr Scand Suppl 350:14-20

26. Larson M, Folstein S (2000) Selective serotonin reuptake inhibitorinduced mydriasis. J Am Acad Child Adolesc Psychiatry 39:138-139

27. Schmitt JA, Riedel WJ, Vuurman EF, Kruizinga M, Ramaekers JG (2002) Modulation of the critical flicker fusion effects of serotonin reuptake inhibitors by concomitant pupillary changes. Psychopharmacology (Berl) 160:381-386

28. Knaggs RD, Crighton IM, Cobby TF, Fletcher AJ, Hobbs GJ (2004) The pupillary effects of intravenous morphine, codeine, and tramadol in volunteers. Anesth Analg 99:108-112

29. Murray RB, Adler MW, Korczyn AD (1983) The pupillary effects of opioids. Life Sci 33:495-509

30. Lee HK, Wang SC (1975) Mechanism of morphine-induced miosis in the dog. J Pharmacol Exp Ther 192:415-431

31. Prow MR, Martin KF, Heal DJ (1996) 8-OH-DPAT-induced mydriasis in mice: a pharmacological characterisation. Eur $\mathrm{J}$ Pharmacol 317:21-28

32. Duman EN, Kesim M, Kadioglu M, Yaris E, Kalyoncu NI, Erciyes N (2004) Possible involvement of opioidergic and serotonergic mechanisms in antinociceptive effect of paroxetine in acute pain. J Pharmacol Sci 94:161-165
33. Kesim M, Duman EN, Kadioglu M, Yaris E, Kalyoncu NI, Erciyes N (2005) The different roles of 5-HT(2) and 5-HT(3) receptors on antinociceptive effect of paroxetine in chemical stimuli in mice. J Pharmacol Sci 97:61-66

34. Singh VP, Jain NK, Kulkarni SK (2001) On the antinociceptive effect of fluoxetine, a selective serotonin reuptake inhibitor. Brain Res 915:218-226

35. Erjavec MK, Coda BA, Nguyen Q, Donaldson G, Risler L, Shen DD (2000) Morphine-fluoxetine interactions in healthy volunteers: analgesia and side effects. J Clin Pharmacol 40:1286-1295

36. Gordon NC, Heller PH, Gear RW, Levine JD (1994) Interactions between fluoxetine and opiate analgesia for postoperative dental pain. Pain 58:85-88

37. Ferrari A, Coccia CP, Bertolini A, Sternieri E (2004) Methadone - metabolism, pharmacokinetics and interactions. Pharmacol Res 50:551-559

38. Tateishi T, Krivoruk Y, Ueng YF, Wood AJ, Guengerich FP, Wood M (1996) Identification of human liver cytochrome P-450 3A4 as the enzyme responsible for fentanyl and sufentanil N-dealkylation. Anesth Analg 82:167-172

39. Kobayashi K, Yamamoto T, Chiba K, Tani M, Shimada N, Ishizaki T, Kuroiwa Y (1998) Human buprenorphine Ndealkylation is catalyzed by cytochrome P450 3A4. Drug Metab Dispos 26:818-821

40. Liu YT, Hao HP, Liu CX, Wang GJ, Xie HG (2007) Drugs as CYP3A probes, inducers, and inhibitors. Drug Metab Rev 39:699-721

41. Link B, Haschke M, Grignaschi N, Bodmer M, Aschmann YZ, Wenk M, Krahenbuhl S (2008) Pharmacokinetics of intravenous and oral midazolam in plasma and saliva in humans: usefulness of saliva as matrix for CYP3A phenotyping. Br J Clin Pharmacol $66: 473-484$

42. Kirchheiner J, Schmidt H, Tzvetkov M, Keulen JT, Lotsch J, Roots I, Brockmoller J (2007) Pharmacokinetics of codeine and its metabolite morphine in ultra-rapid metabolizers due to CYP2D6 duplication. Pharmacogenomics J 7:257-265

43. Koren G, Cairns J, Chitayat D, Gaedigk A, Leeder SJ (2006) Pharmacogenetics of morphine poisoning in a breastfed neonate of a codeine-prescribed mother. Lancet 368:704

44. Stamer UM, Stuber F, Muders T, Musshoff F (2008) Respiratory depression with tramadol in a patient with renal impairment and CYP2D6 gene duplication. Anesth Analg 107:926-929 